\title{
COLETA E TRANSPORTE DE ÁGUA análise e proposta de produto ergonômico modelado em situação de referência
}

\author{
lago Andrew de Oliveira Silva \\ Layane Nascimento de Araújo \\ Steffane Luiza Costa Neves \\ Juliana Donato de Almeida Cantalice
}

\begin{abstract}
Resumo: O presente artigo possui ênfase na descrição e detalhamento do desenvolvimento de um coletor - transportador de água para populações desassistidas, que realizam essa atividade para sua subsistência. Através de uma abordagem metodológica modelada em situação de referência na cidade de viçosa no estado de alagoas, bem como em revisão teórica aliada a pesquisa empírica através de métodos observacionais e interacionais com o referido público alvo, foi proposta uma solução de produto baseado nos princípios da ergonomia. A solução apresentada buscou atender às principais demandas ergonômicas identificadas com as análises, buscando através do design e da ergonomia, melhorar a qualidade da execução da atividade e, consequentemente, a qualidade de vida dessas populações.
\end{abstract}

Palavras-chave: design de produto, ergonomia, coleta e transporte de água

\section{INTRODUÇÃO}

Sabe-se que o acesso a serviços básicos de saneamento é um direito de todos. Entretanto, na prática, há um grande desequilíbrio entre as regiões do Brasil com relação à distribuição igualitária de saneamento básico. No Nordeste, em determinadas regiões do estado de Alagoas, a ausência de água encanada é a realidade de populações que para realizarem suas atividades básicas, submetem-se por muitas vezes a condições precárias. Para ter acesso à água, essas populações necessitam recorrer a fontes alternativas, na qual realizam a coleta e o transporte através de recipientes por um longo percurso, sujeitando-se a condições inadequadas de manejo e transporte.

Esses fatores, por sua vez, podem resultar em problemas ergonômicos - a curto, médio e longo prazo - prejudiciais a qualidade de vida daqueles que precisam realizar esse tipo de atividade para sua própria subsistência. Nessa perspectiva, também se observou uma lacuna no mercado devido à não existência de produtos que se adequem às características socioeconômicas dessas populações. Através dessa lacuna, percebese o importante papel do design em gerar alternativas que possam vir a solucionar as demandas relacionadas a populações desassistidas, por meio do desenvolvimento de soluções que atendam tais necessidades.

Assim, o presente artigo possui ênfase em um estudo de caso realizado na cidade de Viçosa, localizada no estado de Alagoas, o qual através de uma pesquisa de campo fundamentada em métodos interacionais e observacionais, visa expor uma análise 
ergonômica acerca do transporte e manejo de água por parte dessas populações, seguida de uma proposta de produto que possa auxiliar os moradores de regiões que não possuem acesso à água encanada em suas casas, ou não possuem sistemas de distribuição adequados. Para tanto, foram utilizados métodos propostos por diversos autores, configurando-se em uma abordagem metodológica linear, com possibilidades de feedbacks flexíveis entre as fases, e modelada na situação de referência, objetivando assim, chegar a uma proposta de solução em design para o problema em questão.

\section{SANEAMENTO, DESIGN E ERGONOMIA}

A ausência de saneamento aliada a fatores socioeconômicos podem ser observadas em algumas localidades no estado de Alagoas, onde segundo o Decreto № 52.216 do Diário Oficial do Estado De Alagoas - DOEAL, foi declarado em fevereiro de 2017 estado de emergência em 77 municípios afetados pela seca. Ainda de acordo com reportagem veiculada em jornal de circulação em meio eletrônico (77 municípios de AL pedem decreto de emergência por conta da seca - Globo, 2017), já são cerca de seis anos com chuvas abaixo da média em Alagoas. Na cidade de Viçosa, localizada a 96 km da capital Maceió, no período de novembro de 2016 a fevereiro de 2017 os rios encontravam-se praticamente secos e grande parte da população não possuía água na torneira de suas casas há meses.

Figura 1 - Localização de Viçosa no estado de Alagoas. Fonte: elaborado pelos autores, com base na pesquisa realizada (2017).

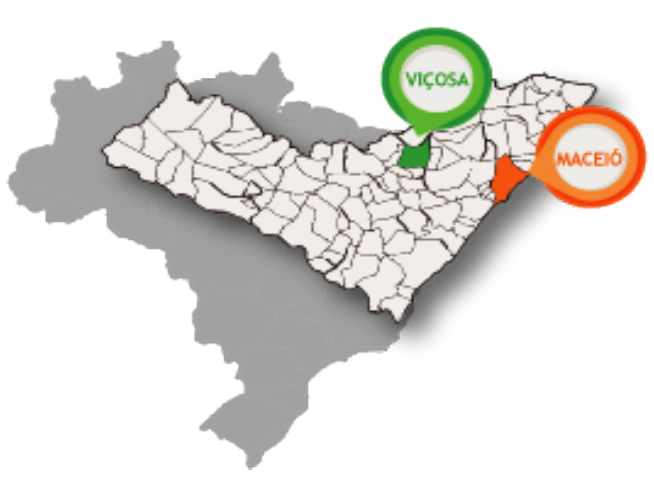

Para garantir a própria subsistência, diversos moradores percorrem longos trechos transportando recipientes para buscar água em fontes alternativas como poços, cacimbas e bicas, submetendo-se por muitas vezes a condições físicas inadequadas, em virtude da ausência de um objeto ergonomicamente apropriado para esta coleta, manejo e transporte. Nessa perspectiva, o papel do designer consiste em desenvolver soluções que sejam capazes de suprir as necessidades dos usuários. Bonsiepe (2012), acrescenta que a função do design está justamente na otimização da relação usuário e produto, contribuindo para o processo de desenvolvimento deste de forma integrada, onde a aparência do produto não deve ser interpretada de forma especial como algo agregado, mas sim conforme a estrutura da solução.

Sendo o design um campo multidisciplinar, além dos aspectos emocionais, morfológicos e funcionais, a ergonomia deve ser parte integrante do desenvolvimento de produtos, uma vez que, conforme o conceito da Associação Brasileira de Ergonomia ABERGO (2000), a mesma caracteriza-se como estudo das interações das pessoas com a tecnologia, a organização e o ambiente, objetivando intervenções e projetos que visem melhorar, de forma integrada e não dissociada, a segurança, o conforto, o bem-estar e a eficácia das atividades humanas. 
Com isso, realizou-se uma análise em situação de referência na cidade de Viçosa localizada no estado de Alagoas, como ilustra a Figura 1, objetivando integrar o design, a ergonomia e a inovação através da identificação de demandas durante a coleta, manejo e transporte de água de populações desassistidas. Visando assim, desenvolver uma solução para a melhoria da qualidade de vida dos usuários, tendo em vista que os materiais e métodos atualmente utilizados não são adequados para a atividade e para o conforto físico dos mesmos.

\section{METODOLOGIA}

De acordo com Löbach (2001), todo processo de design é tanto um processo criativo como um processo de solução de problemas. 0 autor coloca que o processo de design pode se desenvolver de forma complicada dependendo da magnitude do problema a ser resolvido, e para tanto, esse processo é dividido em quatro fases distintas. Tais fases projetuais são: I) Análise do problema; II) Geração de alternativas; III) Avaliação das alternativas; e IV) Realização da solução do problema.

Com base nisso, para o estudo apresentado, foi utilizada uma abordagem metodológica modelada, adaptando as fases propostas por Löbach (2001) e complementando-as com diversas ferramentas propostas por teóricos. Contudo, a pesquisa contará com uma metodologia projetual linear, com possibilidades de feedbacks flexíveis entre as fases, objetivando assim, chegar a uma solução de produto ideal para o problema abordado. A Estrutura Analítica do Projeto (EAP) configurou-se da seguinte forma:

Figura 2 - Estrutura Analítica do Projeto (EAP). Fonte: elaborado pelos autores, com base na pesquisa realizada (2017).

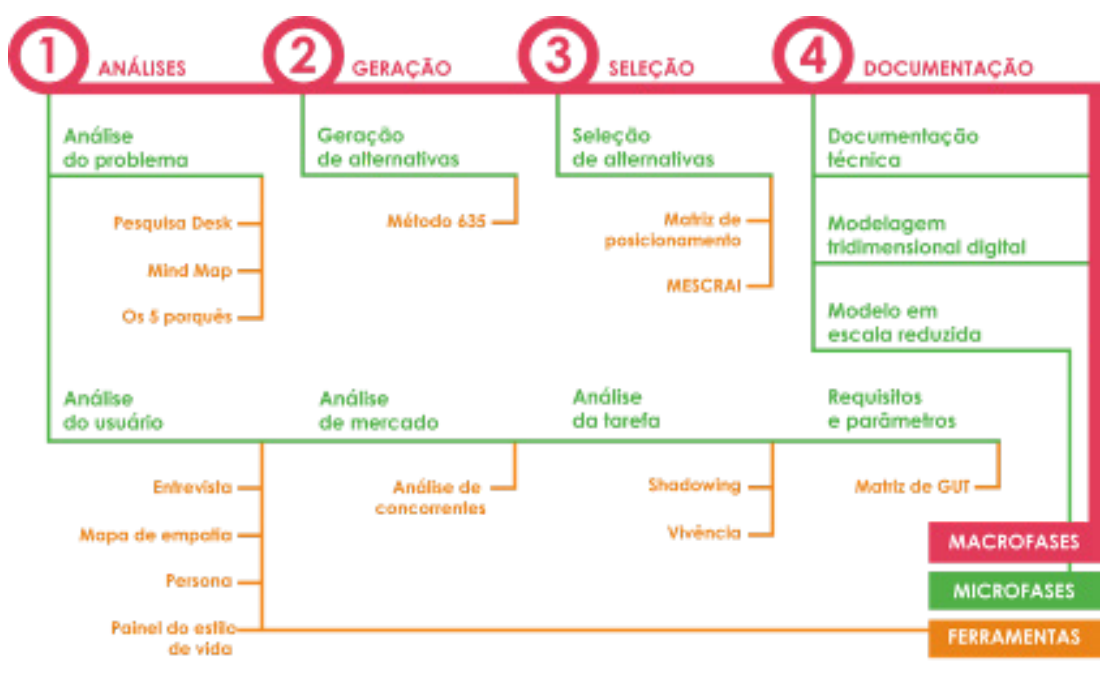

Dentre as etapas realizadas na fase de análises, destacam-se a utilização dos 5 Porquês, a entrevista no local de referência e etapa de análise da tarefa. A primeira consiste em uma proposta de Baxter (2005), que leva à exploração e expansão do problema. A ferramenta dos 5 porquês, pode revelar um novo conjunto de soluções potenciais. Assim, através de sua aplicação percebeu-se que a causa dos problemas em questão, está intrinsecamente relacionada à ausência de um objeto que proporcione o transporte e manejo de água de forma ergonomicamente adequada e impactando positivamente na qualidade de vida dessa população. A responsabilidade governamental quanto a resolução dos problemas relacionados ao abastecimento de água, também foi indicada como uma das justificativas para a ausência de produtos que se adequem às características socioeconômicas dos usuários. 
A seguir, deu-se início a uma análise de usuário, etapa onde o projetista conhece o universo do referido público-alvo e suas características. Para a realização desta análise, a equipe estabeleceu como situação de referência, um estudo de caso de da cidade de Viçosa-AL, na qual vinha sofrendo com um dos maiores índices de falta de abastecimento de água encanada.

Para tanto, a primeira ferramenta realizada foi a Entrevista, que consiste em um método interacional cujo principal objetivo é reunir dados referentes a informações pessoais dos usuários, bem como desejos e necessidades acerca do problema central. Assim, foram realizadas entrevistas de caráter semiestruturado e abertas, aplicadas com 10 pessoas residentes na cidade de Viçosa-AL, que necessitam coletar e transportar água de fontes como poços, cacimbas, bicas e caminhões-pipa oferecidos pela prefeitura da cidade semanalmente. Com os dados coletados, foi possível destacar os importantes aspectos transcritos na Figura 3 abaixo.

Figura 3 - Dados coletados em entrevista. Fonte: elaborado pelos autores, com base na pesquisa realizada (2017).

\begin{tabular}{|c|c|}
\hline $\begin{array}{l}\text { Os usuários possuem em média } 38 \text { anos, onde o } \\
\text { entrevistado mais novo possul } 14 \text { anos e o mais velho } 62 \\
\text { Em sua maioria são muheres.māes. }\end{array}$ & $\begin{array}{l}\text { Utilizam a água para funçōes básicas domésticas. } \\
\text { Entretanto, usuários que nōo possuem } \\
\text { condiçōes econômicas de comprar água } \\
\text { mineral, utilizam para consumo próprio }\end{array}$ \\
\hline $\begin{array}{r}\text { donas de casa e/ou aposenta } \\
\text { Captam água de diversas fontes como } \\
\text { tomeiras públicas, poços. } \\
\text { caminhao-pipa e cacimbas }\end{array}$ & $\begin{array}{l}\text { Transportam a água em recipientes e } \\
\text { vasilhames como baldes e garrafas e } \\
\text { levam até suas casas a pé ou como } \\
\text { auxilio do carro-de-mào }\end{array}$ \\
\hline $\begin{array}{r}\text { Percarrem em média } 350 \mathrm{~m} \text { de suas casas } \\
\text { até essas fontes, sendo a menor distáncia } \\
\text { relatada } 15 \mathrm{~m} \text { e a maior } 600 \mathrm{~m}\end{array}$ & $\begin{array}{l}\text { Afirmam que sentem dores na coluna e } \\
\text { nas mãos em virfude do peso carregado } \\
\text { e do longo percusso percorrido }\end{array}$ \\
\hline $\begin{array}{l}\text { Percomem essa distáncia em média } 8 \text { vezes } \\
\text { ao dia, porém um usuário relatou que necessita }\end{array}$ & $\begin{array}{l}\text { pós a coleta, amazenam a água em baldes } \\
\text { iiores ou caixas d'água }\end{array}$ \\
\hline realizar essa atividade em torno de 20 vezes & \multirow{2}{*}{$\begin{array}{l}\text { Afirmam que a água coletada nōo é filtrada, e por } \\
\text { muitas vezes os próprios usuários utilizam-se de cloreto } \\
\text { ou água sanitária para uma filtragem artesanal; }\end{array}$} \\
\hline Carregam uma média de 28 litros por viagem, sendo $10 \mathrm{~L}$ & \\
\hline o peso mínimo relatado e 105 lifros c & \multirow{2}{*}{$\begin{array}{l}\text { Acrecitam que esse transporte pode melhorar se eles } \\
\text { possuissem objetos com mecanismos de rolagem } \\
\text { ou objetos motorizados }\end{array}$} \\
\hline Reaizam a atividade individualmente e em grupo & \\
\hline
\end{tabular}

Uma das etapas mais importantes do projeto foi a Análise da Tarefa, que se trata de uma das etapas da Análise Ergonômica do Trabalho (AET), proposta por Vidal (2008) e Wisner (1987), consistindo em um método que assegura a positividade da transformação por suas características e propriedades de foco, ordenação e sistematicidade, a partir da aplicação de métodos observacionais e interacionais. Nesta fase, é analisado como o usuário pesquisado comportar-se durante a execução de suas atividades, assim como os procedimentos, equipamentos, ambiente e condicionantes temporais que influenciam diretamente ou indiretamente no exercício da mesma.

Para realizar esta etapa, foi feita uma pesquisa de campo em alguns pontos do centro da cidade de Viçosa-AL, e posteriormente foi utilizada a ferramenta Shadowing, que é um método de pesquisa desenvolvido pela IDEO, empresa internacional de Design, que busca através de uma observação intensa por um período de tempo informações preciosas sobre contextos onde um determinado produto está inserido.

A equipe de projeto utilizou-se de métodos observacionais, através de registros fotográficos, filmagens e anotações, para obtenção de informações importantes a respeito da usabilidade do produto estudado: os coletores e transportadores de água utilizados pelo público em Viçosa-AL. Como se pode observar nos registros abaixo: 
Figura 4 - Moradores transportando água em Viçosa-AL. Fonte: acervo dos autores (2017).

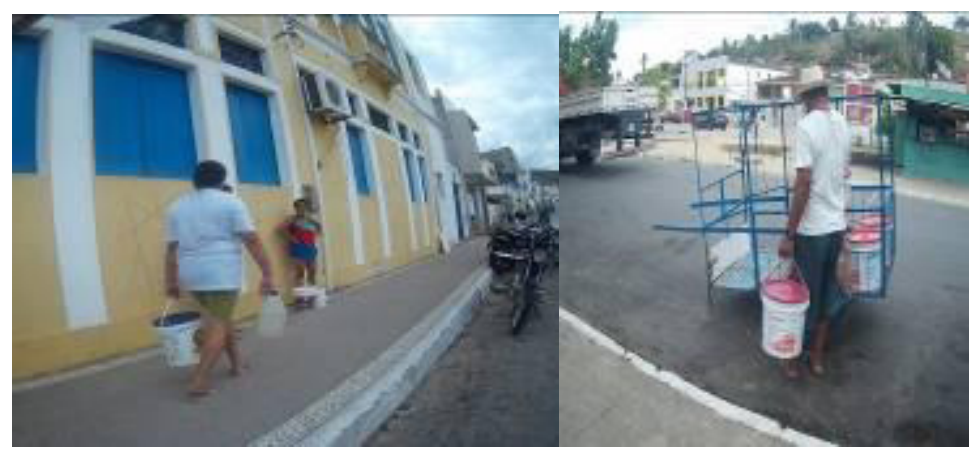

Nesta etapa, também foi feita uma análise com base na antropotecnologia (Wisner, 2003) conforme a Figura 5. A mesma consiste em analisar as etapas de relacionamento do usuário com um produto ou serviço, através de métodos interacionais, que possibilitam a imersão da equipe na atividade realizada pelo público pesquisado e descreve os passos percorridos antes, durante e depois da sua utilização.

O termo antropotecnologia partiu das palavras Antropologia - ciência que estuda a humanidade - e Tecnologia - conjunto ordenado de saberes com fins específicos. A antropotecnologia busca adaptar as intervenções nas situações de trabalho, particularmente nas transferências de tecnologias, analisando fatores técnicos, culturais, sociais, econômicos, geográficos, jurídicos, dentre outras peculiaridades da situação" (WISNER, 2003).

Figura 5 - Membros da equipe do projeto realizando a tarefa. Fonte: acervo dos autores (2017).

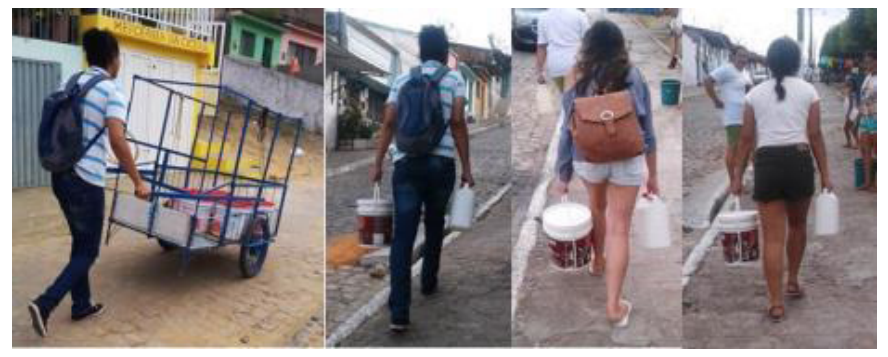

Após as ferramentas aplicadas na análise da tarefa, realizou-se uma Análise Ergonômica da Atividade, tanto por aplicação de métodos observacionais, através de coleta de dados audiovisuais para análise do usuário em si, como de métodos interacionais, realizados pela própria equipe de projeto. Após a análise ergonômica, foi possível estabelecer os problemas ergonômicos recorrentes no transporte e coleta de água pelo público alvo abordado, apresentados no Quadro 1 a seguir:

Quadro 1 - Relação dos problemas ergonômicos identificados. Fonte: elaborado pelos autores com base na pesquisa realizada (2017).

\begin{tabular}{|l|}
\hline PROBLEMAS ERGONÖMICOS IDENTIFICADOS \\
\hline Alongamento vertical excessivo nos braços \\
\hline Excesso de carga transportada \\
\hline Pressão/desconforto na mão \\
\hline Pegas inadequadas para a atividade \\
\hline $\begin{array}{l}\text { Inadequação postural durante } 0 \\
\text { levantamento de cargas }\end{array}$ \\
\hline
\end{tabular}


Picos de tensão

Deslocamento de peso excessivo

Assimetria do peso da carga

Com base nos dados levantados, torna-se possível definir os requisitos e parâmetros projetuais utilizados para verificar as necessidades do mercado e dos referidos usuários, bem como suas demandas, estabelecendo os principais dados qualitativos e quantitativos do projeto, como mostra o Quadro 2 a seguir.

Quadro 1-Requisitos e parâmetros projetuais. Fonte: elaborado pelos autores com base na pesquisa realizada (2017).

\begin{tabular}{|c|c|}
\hline REQUISITOS & PARÁMETROS \\
\hline $\begin{array}{l}\text { Atender às fundamentações teóricas com } \\
\text { base na ergonomia }\end{array}$ & $\begin{array}{l}\text { Projetar para atender às necessidades físicas } \\
\text { dos usuários (ser ergonômico) }\end{array}$ \\
\hline Apresentar boa manobrabilidade & $\begin{array}{l}\text { Minimização do esforço através de indicações } \\
\text { ergonômicas }\end{array}$ \\
\hline $\begin{array}{l}\text { Minimizar a quantidade de viagens } \\
\text { necessárias para a realização da atividade }\end{array}$ & $\begin{array}{l}\text { Aumentar a capacidade de transporte } \\
\text { durante cada percurso sem comprometer a } \\
\text { usabilidade }\end{array}$ \\
\hline $\begin{array}{l}\text { Minimizar o esforço durante } \\
\text { o transporte da carga }\end{array}$ & $\begin{array}{l}\text { Utilizar características de equipamentos de } \\
\text { transporte na configuração do produto }\end{array}$ \\
\hline $\begin{array}{l}\text { Adequar pega/manejo à atividade } \\
\text { executada }\end{array}$ & $\begin{array}{l}\text { Utilizar indicações ergonômicas referentes a } \\
\text { pegas e manejos adequadas à atividade }\end{array}$ \\
\hline $\begin{array}{l}\text { Analisar possibilidades de filtragem de } \\
\text { água do produto }\end{array}$ & $\begin{array}{l}\text { Verificar materiais com propriedades que não } \\
\text { influenciam na característica da água }\end{array}$ \\
\hline $\begin{array}{l}\text { Garantir o armazenamento adequado de } \\
\text { água durante o seu transporte }\end{array}$ & $\begin{array}{l}\text { Desenvolver características morfológicas que } \\
\text { impossibilitem o desperdício de água durante } \\
\text { seu transporte }\end{array}$ \\
\hline
\end{tabular}

Após a definição dos requisitos e parâmetros projetuais, utilizou-se a ferramenta denominada Matriz de GUT proposta por Kepner e Tregoe (1981), cujo principal objetivo é hierarquizar os requisitos de acordo com sua relevância. A mesma possui como objetivo classificar em ordem decrescente de pontos, os requisitos a serem solucionados com prioridade durante o processo.

Dessa forma foi constatado após a aplicação da ferramenta, que os critérios em questão apresentam a seguinte ordem de relevância: 1) Ser ergonômico; 2) Minimizar esforço durante o transporte da carga; 3) Minimizar quantidades de viagens necessárias; 4) Adequar pega/manejo à atividade; 5) Aumentar capacidade de transporte de água em litros; 6) Possuir boa manobrabilidade; 7) Garantir armazenamento adequado para a água; 8) Possibilidade de filtragem da água coletada.

\section{Geração de alternativas}

Löbach (2001) afirma que depois do início do processo de design, analisa-se o problema com seu entorno, e em seguida são geradas as alternativas para o mesmo. É a fase da produção de ideias baseando-se nas análises realizadas, onde a mente precisa trabalhar livremente, sem restrições, para gerar a maior quantidade possível de alternativas.

Tendo isso em vista, foram utilizados métodos de criatividade como o Método 635, o Método de Seleção de Oportunidades e MESCRAI, todas as ferramentas propostas por Baxter (2005), com o objetivo de gerar um maior número de alternativas. O produto final foi proposto com base nos requisitos e parâmetros projetuais previamente estabelecidos neste artigo. Assim, o mesmo foi pensado para reduzir o esforço dos usuários que necessitam coletar água em fontes alternativas para suas residências, bem como reduzir o número de viagens que esses realizam para tal atividade. Para isso, foram estudados e 
analisados conceitos ergonômicos apresentados anteriormente, bem como mecanismos e materiais que pudessem auxiliar nesse transporte. A seguir, será apresentada a composição final do produto.

\section{RESULTADOS E DISCUSSÕES}

O coletor e transportador de água foi desenvolvido visando atender aos requisitos e parâmetros projetuais estabelecidos ao longo do processo projetual. Dessa maneira, tem-se que a forma cilíndrica do produto, ilustrada naFigura 5, foi pensada para que o mesmo pudesse rolar e ser facilmente empurrado, além de aproveitar todo o seu interior como fonte de armazenamento de água e pré-filtragem. A parte de armazenamento de água é dividida em 4 partes iguais, que encaixam-se umas às outras para obtenção do sistema como um todo. Cada módulo individual apresenta aberturas e um sistema de pré-filtragem funcionando como recipiente de armazenamento quando não estiver sendo utilizado como componente para o sistema de transporte e rolagem.

Figura 6 - Ilustração digital. Fonte: elaborado pelos autores, com base na pesquisa realizada (2017).

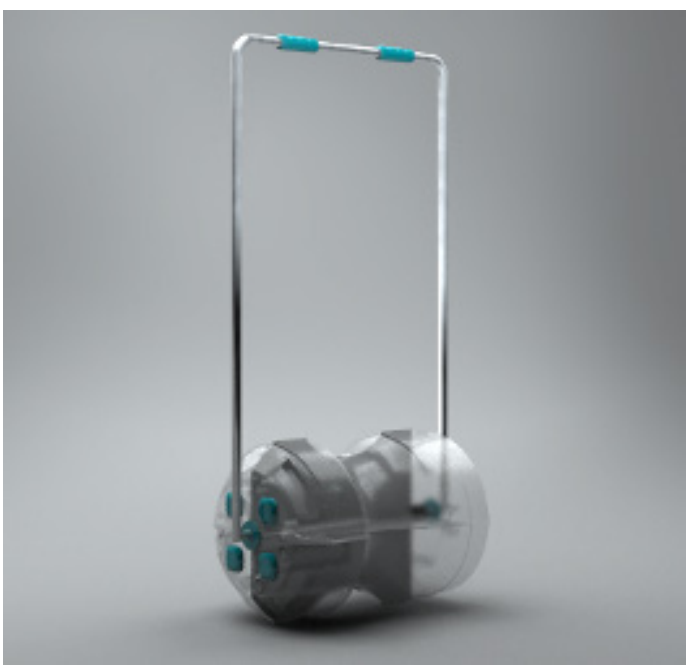

O produto proposto apresenta como material principal o polímero, tipo PET translúcido, o que poderá conferir maior durabilidade quanto aos desgastes ao qual será submetido quando passar por caminhos irregulares. O polímero revestirá a parte do corpo do produto e possuirá uma espessura de $5 \mathrm{~mm}$. Em seu interior será utilizada uma camada de alumínio como revestimento, com o objetivo de auxiliar o processo de pré-filtragem através da absorção do calor e o aumento de temperatura da água coletada.

Em suas dimensões, o produto possuirá altura total (corpo do produto e alça) de 1,20m, esta definição considera a inclinação necessária para aplicação de força na alça durante a execução da atividade. 0 recipiente possui $36 \mathrm{~cm}$ de altura, largura de $50 \mathrm{~cm}$ e raio de $18 \mathrm{~cm}$, com o objetivo de maximizar o armazenamento de água. Tais medidas foram conferidas para que se garantisse uma capacidade de 50 litros de água que poderá ser carregada por viagem do público-alvo durante a utilização do produto, em virtude de que os usuários carregavam aproximadamente 28 litros por viagem.

A alça do produto apresenta material de aço tubular, com dimensões de $20 \mathrm{~mm}$ de espessura, e altura de 1,02 m. Esse material foi escolhido pois proporciona maior resistência e fácil moldagem. A pega/manejo foi pensada seguindo os conceitos ergonômicos para manejo grosseiro com formato anatômico. O material escolhido foi silicone, já que o mesmo poderá ser acoplado a alça e movimentado. 
Como citado anteriormente, o produto possui 4 partes iguais que são encaixadas umas às outras e podem ser utilizadas separadamente. O usuário desencaixa a alça do produto, manuseia um de seus recipientes e o enche de água. Após a coleta, os módulos são agrupados através de encaixes macho e fêmea, resultando em uma forma única cilíndrica, ideal para facilitar o rolamento. Para o manuseio e transporte, o produto dispõe de pegas anatômicas para maior conforto físico durante o manejo grosseiro, e o usuário posiciona a alça de acordo com a sua altura e o empurra até o seu destino final. Como pode ser observado na Figura 7.

Figura 7 - Esquema de usabilidade do produto. Fonte: elaborado pelos autores, com base na pesquisa realizada (2017).

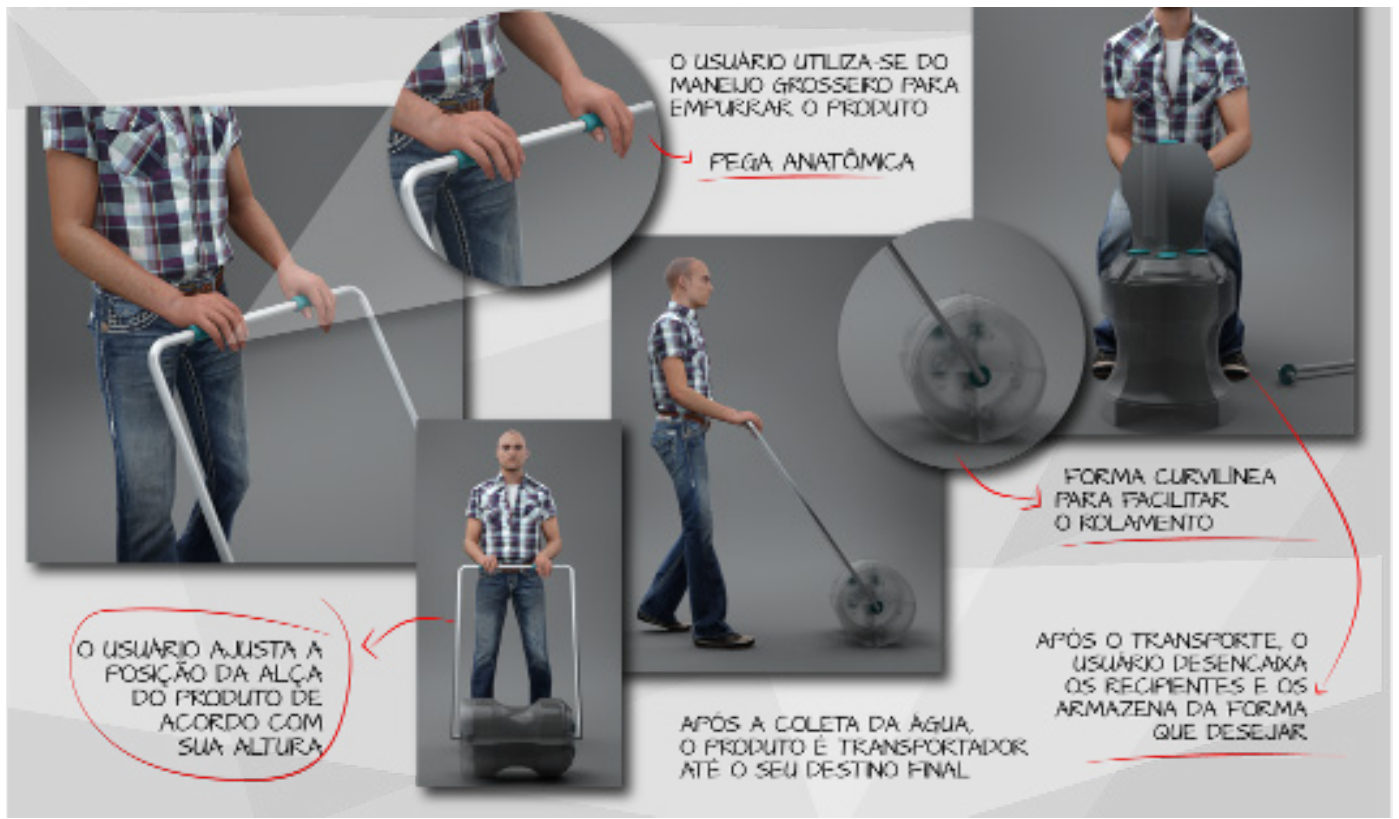

Visando o conforto físico do usuário, o produto foi desenvolvido seguindo os critérios da ergonomia previsto nas etapas de análise da tarefa e análise ergonômica vistas nos estudos realizados anteriormente. Assim, a alça do produto, na posição de 90ํo graus, localiza-se a 1,2 metros do chão, possibilitando ao usuário ajustar sua inclinação de acordo com sua altura, utilizando-se do peso do usuário para facilitar a movimentação do mesmo. A pega de silicone localizada na alça do produto possui formato anatômico, facilitando o manuseio e oferecendo maior conforto durante a execução da atividade, uma vez que a pega anatômica, evita criar picos de tensão e estrangulamento dos vasos sanguíneos, não criando incômodos táteis.

Cada módulo do produto individualmente apresenta formato de um quarto de círculo. As divisões facilitam ao usuário a movimentação do líquido, uma vez que cada módulo comporta aproximadamente 12,5 litros (equivalente a aproximadamente 12,5kg), garantindo que o usuário consiga movimentá-lo sem realização de esforços extremos. As pegas disponíveis em cada módulo possibilitam, caso necessário, que o usuário carregue ao mesmo tempo, de forma equivalente, um módulo em cada mão. Essa utilização é recomendada para quando o usuário estiver armazenando o produto em sua residência.

Dessa maneira, têm-se que os mecanismos adotados na concepção da proposta de produto, foram conferidos seguindo embasamentos teóricos com base nos princípios da ergonomia, visando garantir melhor usabilidade e bem-estar físico para os usuários durante a coleta, manejo e transporte do produto em questão. 


\section{CONSIDERAÇÕES FINAIS}

A pesquisa aqui abordada foi realizada através da análise e vivência da situação de referência da cidade de Viçosa-AL, onde foi possível observar que os materiais e métodos utilizados pela população local para coleta e transporte de água, não são adequados para a realização desta atividade, podendo acarretar em problemas ergonômicos a curto, médio e longo prazo, em virtude das condições físicas inadequadas, tais como: postura incorreta, transporte excessivo de carga, pegas e manejos inapropriados, resultando em um esforço imoderado dos usuários.

Desse modo, com as ferramentas metodológicas utilizadas e apresentadas no desenvolvimento do projeto, chegou-se aos requisitos e parâmetros projetuais que nortearam a etapa de geração de alternativas, e através de modelagens tridimensionais e mockups foi possível chegar à proposta de solução final apresentada anteriormente.

A solução visa atender às principais necessidades identificadas pela equipe, como diminuir ergonomicamente o esforço físico e o número de viagens que são dados pelo público que realiza essa atividade de coleta e transporte de água. Além de que, foi também proposto um método de pré-filtragem para ajudar a acelerar o consumo da água coletada.

Em suma, o projeto proposto visa atender às expectativas apresentadas inicialmente, que consiste na melhoria da atividade de coleta e transporte por parte das populações desassistidas que não dispõem de água encanada em suas residências e/ou que por algum motivo passa por uma situação mesmo que temporária de escassez de água, objetivando assim, melhorar a qualidade de vida desse público, garantindo menos desconforto físico durante a execução dessa atividade.

\section{REFERÊNCIAS}

ABERGO (Associação Brasileira de Ergonomia). O que é Ergonomia?. Disponível em: http://www.abergo.org.br/. Acesso em: 07 mar. 2017.

BAXTER, M. R. Projeto de Produto: Guia Prático para o Design de Novos Produtos. São Paulo: Editora Blücher, 2005.

Projeto de Produto: Guia Prático para o Design de Novos Produtos. São Paulo: Editora Blücher, 2015.

BONSIEPE, Gui. Design como prática de projeto. São Paulo: Blucher, 2012.

BROWN, Tim. Design thinking: uma metodologia poderosa para decretar o fim das velhas ideias. Rio de Janeiro: Elsevier, 2010.

LÖBACH, Bernd. Design Industrial: Bases para a configuração dos produtos industriais. Tradução de Freddy Van Camp. São Paulo: Blucher, 2001.

NIEMEYER, L. Código de ética para designers. Disponível em <http://www.design.com. br/blog/codigo-de-etica-para-designers/>. Acesso em: 09 maio. 2017.

VIDAL, M. C. R. Guia para Análise Ergonômica do Trabalho (AET) na empresa: uma metodologia realista, ordenada e sistemática. Rio de Janeiro: Virtual Científica, 2008.

WISNER, A. A Inteligência no Trabalho: Textos selecionados de Ergonomia. $2^{\circ}$ ed. São Paulo: FUNDACENTRO, 2003.

; Por dentro do trabalho: ergonomia, método e técnica. Tradução Flora Maria Gomide Vezzá. São Paulo: FTD / Oboré, 1987. 
Sobre os autores

lago Andrew de Oliveira Silva (graduando), UFAL <iagoandrew2国gmail.com> Layane Nascimento de Araúio (graduanda), UFAL <layane.n.araujo@gmail.com> Steffane Luiza Costa Neves (graduanda), UFAL <steffaneluiza@hotmail.com> Juliana Donato de Almeida Cantalice (doutranda), UFAL <juliana.donato@fau.ufal.br> 